Original Article

\title{
Effects of flexi-bar and non-flexi-bar exercises on trunk muscles activity in different postures in healthy adults
}

\author{
Jun Sub Chung, PT, MS ${ }^{1)}$, Seol Park, PT, PhD ${ }^{1)}$, JiYoung Kim, PT, MS ${ }^{1)}$, Ji Won Park, PT, PhD ${ }^{1)^{*}}$ \\ 1) Department of Physical Therapy, College of Medical Health, Catholic University of Daegu: 13-13 \\ Hayang-ro, Hayang-eup, Gyeongsan-si, Gyeongbuk 712-902, Republic of Korea
}

\begin{abstract}
Purpose] The purpose of this study was to assess the effects of flexi-bar exercises and non-flexi-bar exercises on trunk muscle activity in different postures in healthy adults. [Subjects] Twenty healthy right-hand dominant adults (10 males and 10 females) were selected for this study. None of the participants had experienced any orthopedic problems in the spine or in the upper and lower extremities in the previous six months. [Methods] The subjects were instructed to adopt three exercise postures: posture 1, quadruped; posture 2, side-bridge; and posture 3, standing. Surface electromyography of selected trunk muscles was normalized to maximum voluntary isometric contraction. [Results] The external oblique, internal oblique, and erector spinae muscle activity showed significant differences between flexi-bar exercises and non-flexi-bar exercises. [Conclusion] The results of this study suggest that flexi-bar exercises are useful in the activation of trunk muscles.

Key words: Flexi-bar, Vibration, Electromyography
\end{abstract}

(This article was submitted Feb. 19, 2015, and was accepted Apr. 16, 2015)

\section{INTRODUCTION}

The spine forms the center of the human body and provides passive stability through bones and ligament tissues and active stability through muscles ${ }^{1}$. In particular, trunk muscle activity precedes movement of the upper and lower extremities in the human body ${ }^{2}$. Impaired and delayed trunk muscle activity leads to unstable upper and lower extremity movement ${ }^{3)}$. Instability of the lumbar vertebrae is one of the primary causes of low back pain ${ }^{4}$.

The muscles that provide active trunk stability are categorized into global and local muscles. The global muscles are relatively large, superficial muscles that surround the abdomen and lumbar vertebrae. They generate torque, and their function is to control the overall trunk stability. The local muscles are the intrinsic muscles located in deep areas of the abdomen and lumbar vertebrae, and their function is to control fine spinal adjustments and stability between spinal segments ${ }^{5)}$. Well-controlled cooperation between the global and local muscles contributes to spinal stability ${ }^{6,7)}$.

Spinal stability is also closely related to co-contraction of the trunk muscles, which is needed to maintain appropriate spinal stability in order to alleviate and prevent low back pain $^{8)}$. In an effort to ascertain how to maintain such spinal

*Corresponding author. Ji Won Park (E-mail: mylovept@ hanmail.net)

C2015 The Society of Physical Therapy Science. Published by IPEC Inc. This is an open-access article distributed under the terms of the Creative Commons Attribution Non-Commercial No Derivatives (by-ncnd) License $<$ http://creativecommons.org/licenses/by-nc-nd/3.0/> . stability, a number of trunk stabilization exercises have been employed and researched clinically in various studies ${ }^{9-11)}$.

When vibration stimulation is applied to muscles, it creates strong proprioceptive stimulation, which significantly affects movement perception in not only healthy people but also in patients with a variety of neurological disorders ${ }^{12)}$. Whole body vibration exercise provides strong sensory stimulation that can activate the muscle spindles and strengthen the proprioceptive senses, thereby strengthening the muscles that are essential for postural stability ${ }^{13)}$.

As movement limitations during daily activities due to trunk muscle problems are common, there are several ongoing studies on trunk muscles activities and exercise methods. Effective exercise tools have also been developed and executed in relation to trunk muscle activation. This study investigates the use of vibration and is based on previous studies in which vibration greatly increased muscle activity. However, few studies have been conducted on vibration exercises that are effective only in a particular region of the body. This study aimed to determine whether flexi-bar and non-flexi-bar exercises, exerting different vibration strengths on the shoulder joints, are effective in trunk muscle activation in different postures.

\section{SUBJECTS AND METHODS}

Twenty healthy right-hand dominant adults (10 males and 10 females) were selected for this study. None of the participants had orthopedic problems in the spine or in the upper and lower extremities in the previous six months. The average height and weight of the subjects were $168.4 \mathrm{~cm}$ and $63.3 \mathrm{~kg}$ respectively while their average body mass index 
(BMI) was $21.4 \mathrm{~kg} / \mathrm{m}^{2}$. All subjects understood the purpose of this study and provided written consent prior to their participation in accordance with the ethical standards of the Declaration of Helsinki.

The flexi-bar (Togu, Germany) used in this study was developed by Dr. Raçef in Germany in the late 1990s and is used as an exercise tool for shoulder joints and the whole body. It generates by creating 270 vibrations per minute $(4.6 \mathrm{~Hz})$. The flexi-bar specifications were as follows: length, weight, and thickness were $153 \mathrm{~cm}, 710 \mathrm{~g}$, and $9.5 \mathrm{~mm}$, respectively. Flexi-bar exercises are physical responses to vibration, which requires stability in the trunk and the proximal region of the arms. The flexi-bar strength can be controlled by changing the weight or thickness of the bar. A general stretching bar was used as the non-flexi-bar, and the length and weight of the non-flexi-bar was set to the same values as those of the flexi-bar.

To measure the electromyography (EMG) signal of the selected muscles, an eight-channel wireless EMG device (WEMG-8, Laxtha, USA) was used. This equipment consists of a transmitter and a receiver, and measures data by transmitting and receiving frequencies wirelessly. Notebook computers and electrode cables were also used as auxiliary equipment.

A practice period of three days in one week was conducted to familiarize subjects with the flexi-bar exercise prior to the experiment. The flexi-bar exercise was performed with as little trunk movement as possible. The movement direction of the bar was from the outside to the inside of the trunk or vice versa. The exercises were performed by the subjects in the three postures described below. First, for the quadruped posture, the subject performed the flexi-bar exercise in the prone position with the knee and hip flexed to $90^{\circ}$, and the left arm supported on the floor. The exercise was conducted while the arm was abducted to $90^{\circ}$ in the anatomical position. Second, a side-bridge posture was adopted as follows: In the side-lying posture, the knees were flexed to $90^{\circ}$, while the hip joints maintained $180^{\circ}$ extension. In this posture, the flexi-bar exercise was performed with the left arm supported on the floor in full extension. Third, for the standing posture, the flexi-bar exercise was performed with the subject standing with feet about shoulder width apart and the arms abducted to $90^{\circ}$ in the anatomical position. The postures adopted for the non-flexi-bar exercise were the same as those used in the flexi-bar exercise.

The surface electrode for the rectus abdominis was attached to the middle of the muscle belly between the umbilicus and the pubic bone, while the external oblique electrode was placed $15 \mathrm{~cm}$ lateral to the umbilicus. The electrode for the internal oblique was attached at the midpoint between the anterior superior iliac spine (ASIS) and the symphysis pubis, while the electrode for the erector spinae was placed $2 \mathrm{~cm}$ lateral to the belly at the height of the first lumbar vertebra. The reference electrode was placed on the inner third of the clavicle shaft. To minimize error due to electrode skin impedance, the regions where the electrodes were placed were shaved, rubbed lightly four times using fine sandpaper, and cleansed with alcohol. EMG values were measured in $\mathrm{uV}$. Any noise caused by cable movement was minimized by arranging the cables neatly between the electrodes and the EMG system. The EMG signals were observed using a computer connected to the EMG system. This was done by setting a channel that corresponded to each connected muscle via a corresponding cable. The sampling rate for the signals collected through the electrodes was set to $1,024 \mathrm{~Hz}$. For the EMG analysis, a band-pass filter of $10-450 \mathrm{~Hz}$ was applied and, notch filters were used at the $60 \mathrm{~Hz}, 120 \mathrm{~Hz}$, and $180 \mathrm{~Hz}$ intervals to prevent them from affecting the frequencies set by the band-pass filter. The first and last data obtained within the first and last two seconds, respectively, from the surface EMG signals were removed from the analysis, and the data were then processed and analyzed using root mean square (RMS).

To standardize the action potential of each muscle, the maximal voluntary isometric contraction (MVIC) was used. MVIC measurement positions were adopted based on a previous study ${ }^{14)}$. Each position was held for 7 seconds to reduce measurement variation at the start and end points of the exercise. The activity of the muscles was measured for 5 seconds, excluding the first and last second.

An independent sample t-test was used to compare the subjects' muscle activities when using the two different bars. The statistical significance level $(\alpha)$ was set at 0.05 , and the collected data were analyzed with the commercial statistics program, SPSS Windows Version 18.0.

\section{RESULTS}

There was a significant difference between muscle activities of the internal oblique in the exercises carried out using the two different bars in the quadruped posture $(p<0.05)$. There was a significant difference between the muscle activities of the internal oblique and erector spinae in the exercises using the two different bars in the side-bridge posture $(\mathrm{p}<0.05)$. There was a significant difference between muscle activities of the internal and external oblique in the exercises using the two different bars in the standing posture $(\mathrm{p}<0.05)$ (Table 1).

\section{DISCUSSION}

This study aimed to determine whether flexi-bar exercises using vibration was effective in stimulating trunk muscle activities during various trunk muscle strengthening exercises, with the subjects in different postures. The objective of the investigation was to obtain information on new exercise programs and their various benefits. To achieve this goal, three postures-quadrupeds, side-bridge, and standing were selected. The subject performed flexi-bar and non-flexi-bar exercises, and muscle activities in the rectus abdominis, external and internal oblique, and erector spinae were compared during the exercises using surface electrodes.

First, there was a significant difference between muscle activities of the internal oblique in the quadruped posture $(p<0.05)$, whereas the other muscles showed no significant difference $(p>0.05)$. Second, there was a significant difference between muscle activities of the external oblique and the erector spinae in the side-bridge posture $(p<0.05)$, whereas the other muscles showed no significant difference $(p>0.05)$. Third, there was a significant difference between 
Table 1. Comparison of the EMG activity of trunk muscles following flexi-bar and non-flexi-bar exercises performed in different postures (Unit: \%MVIC)

\begin{tabular}{lcccccc}
\hline & \multicolumn{2}{c}{ Quadruped position } & \multicolumn{2}{c}{ Side-bridge position } & \multicolumn{2}{c}{ Standing position } \\
\cline { 2 - 7 } & $\begin{array}{c}\text { Non- } \\
\text { flexi-bar }\end{array}$ & Flexi-bar & $\begin{array}{c}\text { Non- } \\
\text { flexi-bar }\end{array}$ & Flexi-bar & $\begin{array}{c}\text { Non- } \\
\text { flexi-bar }\end{array}$ & Flexi-bar \\
\hline RA & $2.4 \pm 0.7$ & $3.0 \pm 1.4$ & $7.2 \pm 1.9$ & $6.7 \pm 1.9$ & $2.8 \pm 1.4$ & $3.3 \pm 1.5$ \\
EO & $26.8 \pm 14.9$ & $39.4 \pm 26.7$ & $26.3 \pm 9.3$ & $32.7 \pm 12.3$ & $19.5 \pm 8.5$ & $26.6 \pm 9.0 *$ \\
IO & $14.1 \pm 4.8$ & $20.0 \pm 7.9 *$ & $10.2 \pm 3.3$ & $17.8 \pm 13.3 *$ & $8.5 \pm 3.1$ & $14.9 \pm 6.2 *$ \\
ES & $49.2 \pm 18.7$ & $66.6 \pm 33.6$ & $10.1 \pm 3.3$ & $18.9 \pm 18.5 *$ & $8.2 \pm 4.3$ & $16.6 \pm 15.0$ \\
\hline
\end{tabular}

${ }^{*} \mathrm{p}<0.05$, RA: rectus abdominis; EO: external oblique; IO: internal oblique; ES: erector spinae

muscle activities of the external and internal oblique in the standing posture $(\mathrm{p}<0.05)$, whereas the rectus abdominis and erector spinae showed no significant difference $(\mathrm{p}>0.05)$.

According to a previous study ${ }^{15}$ ), an external load that makes achieving a balance between upper and lower extremities challenging can accelerate trunk muscle activity, which in turn, contributes to trunk stability. As revealed in previous studies, the present study showed a more significant difference between muscle activities during the flexi-bar exercise than during the non-flexi-bar exercise. This is because the flexi-bar exercise accelerated trunk muscle activity by increasing external loads while overcoming the vibrations exerted from the inside to the outside of the body.

The quadruped posture has been employed in many previous studies to investigate trunk stability. It has been found that in this posture, the trunk muscle activities increase as external loads on the upper and lower extremities increase ${ }^{16)}$. In the present study, the flex-bar exercise carried out in the quadruped posture also showed a significant increase in the muscle activity of the internal oblique. This was because the flexi-bar exerted more external loads than the non-flexi-bar, thereby showing a significant difference between the muscle activities of the internal oblique.

The flexi-bar exercise in the side-bridge posture showed a significant difference between the muscle activities of the internal oblique and erector spinae. Compared to the quadruped posture, the side-bridge posture led to greater muscle activity in the erector spinae of the female subjects than the male subjects during the flexi-bar exercise. This was because the female subjects were unable to accurately control lumbar lordosis, resulting in a significant difference in terms of the erector spinae.

The flexi-bar exercise in the standing posture showed a significant difference between muscle activities of the internal and external oblique. The standing posture occupies a much narrower area of basal plane than the quadruped and side-bridge postures. Thus, in the standing posture, the subjects had to maintain the trunk in a narrower basal plane area, thereby creating a significant difference in terms of the external oblique muscle compared to other postures.

This result was due to the following reasons. A highly efficient movement has been observed in the transversus abdominis, and internal and external obliques among the abdominal muscles, whereas a relatively inefficient movement has been observed in the rectus abdominis ${ }^{17)}$. There was no significant difference found between the muscle activities of the rectus abdominis during isometric right and left axial trunk rotation ${ }^{18)}$. In addition, right and left rotations and trunk imbalance are controlled by the internal and external oblique or the transversus abdominis muscles, which run obliquely or transversely, rather than by the muscles arranged in a longitudinal direction, such as the rectus abdominis ${ }^{19)}$. As such, the present study also showed no significant difference between muscle activities of the rectus abdominis compared to changes in muscle activities of the other trunk muscles. In addition, it showed that the flexi-bar exercise significantly increased muscle activities of the internal oblique in the quadruped posture, internal oblique and erector spinae in the side-bridge posture, and internal and external oblique in the standing posture.

The vibration characteristic of the flexi-bar creates a strong proprioceptive stimulation, which has a significant effect on the movement perceptions in not only healthy individuals but also in patients with a variety of neurological disorders ${ }^{12)}$. In summary, the vibration resulted in the creation of strong external loads by intense stimulation of the muscle proprioceptors, thereby increasing the trunk muscle activities during the exercise.

This study had a few limitations. The subjects were healthy adults in their 20 s, which made generalization of the results to the general population difficult. Furthermore, vibration exercise tool for clinical research will be needed as to whether this applies also to patients.

\section{REFERENCES}

1) MaGill S: Low back disorders evidence-based prevention and rehabilitation. Champaign: Human Kinetics, 2002, pp 17-32.

2) Brill PW, Couzen GS: The core program, 1st ed. New York: Bantam Bantam Books, 2002, pp 88-95.

3) Lehman GJ, Hoda W, Oliver S: Trunk muscle activity during bridging exercises on and off a Swiss ball. Chiropr Osteopat, 2005, 13: 14-21. [Medline] [CrossRef]

4) Leone A, Guglielmi G, Cassar-Pullicino VN, et al.: Lumbar intervertebral instability: a review. Radiology, 2007, 245: 62-77. [Medline] [CrossRef]

5) Bergmark A: Stability of the lumbar spine. A study in mechanical engineering. Acta Orthop Scand Suppl, 1989, 230: 1-54. [Medline] [CrossRef]

6) Marshall PW, Murphy BA: Core stability exercises on and off a Swiss ball. Arch Phys Med Rehabil, 2005, 86: 242-249. [Medline] [CrossRef]

7) Stevens VK, Vleeming A, Bouche KG, et al.: Electromyographic activity of trunk and hip muscles during stabilization exercises in four-point kneeling in healthy volunteers. Eur Spine J, 2007, 16: 711-718. [Medline] [CrossRef]

8) Stevens VK, Bouche KG, Mahieu NN, et al.: Trunk muscle activity in healthy subjects during bridging stabilization exercises. BMC Musculoskelet Disord, 2006, 7: 75-82. [Medline] [CrossRef] 
9) Yoo YD, Lee YS: The effect of core stabilization exercise using a sling on pain and muscle strength of patients with chronic low back pain. J Phys Ther Sci, 2012, 24: 671-674. [CrossRef]

10) Choi $\mathrm{Y}$, Kang H: The effects of sling exercise using vibration on trunk muscle activities of healthy adults. J Phys Ther Sci, 2013, 25: 1291-1294. [Medline] [CrossRef]

11) Akuthota V, Nadler SF: Core strengthening. Arch Phys Med Rehabil, 2004, 85: S86-S92. [Medline] [CrossRef]

12) Cohen LG, Starr A: Vibration and muscle contraction affect somatosensory evoked potentials. Neurology, 1985, 35: 691-698. [Medline] [CrossRef]

13) Bogaerts A, Verschueren S, Delecluse $C$, et al.: Effects of whole body vibration training on postural control in older individuals: a 1 year randomized controlled trial. Gait Posture, 2007, 26: 309-316. [Medline] [CrossRef]

14) Kendall FP, McCreary EK, Provance PG: Muscles; traning and function with posture and pain, 5th ed. Philadelphia: Lippincoot Williams \&
Wilkins, 2005, pp 163-219.

15) Cresswell AG, Oddsson L, Thorstensson A: The influence of sudden perturbations on trunk muscle activity and intra-abdominal pressure while standing. Exp Brain Res, 1994, 98: 336-341. [Medline] [CrossRef]

16) Stevens VK, Coorevits PL, Bouche KG, et al.: The influence of specific training on trunk muscle recruitment patterns in healthy subjects during stabilization exercises. Man Ther, 2007, 12: 271-279. [Medline] [CrossRef]

17) Kavcic N, Grenier S, McGill SM: Determining the stabilizing role of individual torso muscles during rehabilitation exercises. Spine, 2004, 29: 1254-1265. [Medline] [CrossRef]

18) Ng JK, Parnianpour M, Richardson CA, et al.: Functional roles of abdominal and back muscles during isometric axial rotation of the trunk. J Orthop Res, 2001, 19: 463-471. [Medline] [CrossRef]

19) Hall CM, Brody LT: Therapeutic Exercise; Moving toward function, 1st ed. Philadelphia: Lippincott Williams \& Wilkins, 1999. 